\title{
Does a Fracture at One Site Predict Later Fractures at Other Sites? A British Cohort Study
}

\author{
T. P. van Staa ${ }^{1-3}$, H. G. M. Leufkens ${ }^{2}$ and C. Cooper $^{1}$ \\ ${ }^{1}$ MRC Environmental Epidemiology Unit, University of Southampton, Southampton General Hospital, Southampton, UK; \\ ${ }^{2}$ Department of Pharmacoepidemiology and Pharmacotherapy, University of Utrecht, Utrecht, The Netherlands; and ${ }^{3}$ Procter \& \\ Gamble Pharmaceuticals, Staines, UK
}

\begin{abstract}
The extent to which a fracture at one skeletal site predicts further fractures at other sites remains uncertain. We addressed this issue using information from the UK General Practice Research Database, which contains the medical records of general practitioners; our study population consisted of all patients aged 20 years or older with an incident fracture during 1988 to 1998. We identified 222369 subjects (119317 women, 103052 men) who had sustained at least one fracture during follow-up. There was a 2- to 3-fold increase in the risk of subsequent fractures at different skeletal sites. A patient with a radius/ulna fracture had a standardized incidence ratio (SIR) of 3.0 (95\% confidence interval 2.9-3.1) for fractures at a different skeletal site; for initial vertebral fracture, this ratio was $2.9(2.8-3.1)$ and for initial femur/hip fracture it was $2.6(2.5-2.7)$. The SIRs were generally higher among men than women. Men aged 6574 years with a radius/ulna fracture or vertebral fracture had substantially higher rates of subsequent femur/hip fractures than expected; SIRs were 6.0 (3.4-9.9) and 13.4 (7.3-22.5). Corresponding SIRs among women of similar age were $3.3(2.8-3.9)$ and $5.8(4.1-8.1)$, respectively. Men and women aged 65 years or older with a vertebral fracture had a 5-year risk of femur/hip fracture of $6.7 \%$ and $13.3 \%$, respectively. Our results indicate that fractures at any site are strong risk factors for subsequent fractures, among both elderly men and women.
\end{abstract}

Correspondence and offprint requests to: Prof. Cyrus Cooper, MA, DM, FRCP, FMedSci, MRC Environmental Epidemiology Unit, University of Southampton, Southampton General Hospital, Southampton SO16 6YD, UK. Tel: +44 (0)23 8077 7624. Fax: +44 (0)23 8070 4021. e-mail: cc@mrc.soton.ac.uk
Keywords: Epidemiology; Fracture risk; Fractures; Osteoporosis; Risk factors

\section{Introduction}

Prevalent among the elderly, osteoporosis presents a major source of morbidity and high health care costs. It is characterized by low bone density and disruption of bone architecture, which leads to an increased risk of fracture [1]. Bone density can be assessed by noninvasive techniques such as dual-energy X-ray absorptiometry [2]. Several guidelines recommend restricting the use of bone densitometry in the diagnosis of osteoporosis primarily to patients with clinical risk factors for a fracture, such as a previous fragility fracture of the hip, spine or wrist $[3,4]$. Several studies have confirmed that these types of fractures increase the risk of other osteoporotic fractures [5-14]. Best documented is the increased risk of hip fracture following a vertebral fracture, with reports of at least a 2-fold excess [5$8,10,14]$. Forearm fractures increased the risk of subsequent hip fractures by about $50 \%[9,12,13]$. However, less is known about the relationship between fractures at other skeletal sites such as the humerus and whether there are any age- or sex-related differences in the risk of further fracturing. The purpose of the present report is to estimate the extent to which a fracture at one skeletal site predicts further fractures at other sites. Data were obtained on a large group of patients with a fracture in a representative general practice setting. 


\section{Patients and Methods}

General practitioners (GPs) play a key role in the health care system in the United Kingdom, as they are responsible for primary health care and specialist referrals. The information in this study was obtained from the General Practice Research Database (GPRD) that contains the computerized medical records from 683 general practices in the UK, representing approximately $6 \%$ of the total registered population of England and Wales [15]. The data accrued in the GPRD include demographic information about the patient, prescription details, clinical events, preventive care provided, referrals to specialist care, hospital admissions and their major outcomes. Clinical data are stored and retrieved by means of Oxford Medical Information Systems (OXMIS) and READ codes for diseases or causes of morbidity and mortality that are crossreferenced to the International Classification of Diseases, 9th revision (ICD-9). The data quality of each entry into GPRD is measured against specific targets, developed by comparisons with external statistics, to ensure research standards are met. Only data from practices that pass this quality control are compiled to form the GPRD database. Several independent validation studies have shown that the GPRD database has a high level of completeness and validity [16]. The GPRD is owned by the Department of Health and managed by the Medicines Control Agency in the UK.

\section{Study Population}

The study population consisted of all permanently registered patients aged 20 years or older who had a fracture recorded in their medical record during the period of time from the enrolment date of their practice in GPRD up to the end of data collection (i.e., patient's change of practice, death or the end of the study, whichever date came first). Data were collected for this study from 1988 to 1998. The fracture types were classified according to the ICD-9 categories, which included skull (categories 800 to 804 ), vertebral ( 805 or 806), rib (807), pelvis (808), clavicle (810), scapula (811), humerus (812), radius/ulna (813), carpal (814 to $817)$, femur/hip (820 or 821$)$, patella (822), tibia/fibula/ ankle (823 or 824$)$, foot $(825$ or 826$)$ or unspecified fractures $(809,818,819,827$ or 829$)$.

The incidence patterns in the study population of these fractures have been described elsewhere. Women were more likely to experience radius/ulna and femur/hip fractures and men carpus fractures [16]. A validation study reported a high level of validity of the GPRD with respect to fractures. Hip fractures were confirmed by the GP on a questionnaire in $91.0 \%$ and vertebral fracture in $88.1 \%$ of cases. Vertebral fractures were mostly diagnosed on the basis of radiographic measurements and clinical symptoms [17].

For all patients, the first fracture that occurred after the start of data collection was identified. Patients were then followed from the date of this first fracture until they sustained a fracture at a different skeletal site, or until the end of the study. In the case of a patient experiencing fractures at two different sites after their first fracture, each fracture type was considered individually. First and subsequent fractures that occurred at an unspecified location were not included in the analysis. Also, the risk of a repeat fracture at the same or contralateral skeletal site could not be evaluated in this study. Standardized incidence ratios (SIRs) were then calculated in order to assess the influence of a fracture on the risk of subsequent fracture at different skeletal sites. The SIR is the ratio of the observed to expected number of fracture cases during follow-up. The expected number of fracture cases was calculated by multiplying age- and sex-specific incidence rates from the GPRD population for each fracture type by the age- and sex-specific person-years of follow-up. The GPRD fracture incidence rates were the number of patients with a first fracture divided by the total person-time in GPRD (i.e., the sum of the number of patients registered in GPRD at 1 July of each calendar year). The $95 \%$ confidence intervals $(95 \%$ CI) around the SIR were based on Wald confidence limits if the expected number of cases exceeded 10 events and based on the cumulative Poisson distribution if this expected number of cases was 10 or lower [18]. The cumulative incidence over time of patients who did not suffer from a further fracture was estimated using product-limit life table methods.

\section{Results}

A total of 222369 subjects (119317 women, 103052 men) were identified who had sustained at least one fracture during follow-up. Standardized to the population of the UK, the annual rate of fracture was 103.4 fractures per 10000 persons (Table 1). A total of 77828 fracture cases were aged 65 years or over (61 499 women, 16329 men). We explored the association between fractures at different sites in this subsample. The total follow-up of the study subjects

Table 1. Number of patients with a fracture and incidence rates standardized to the UK population

\begin{tabular}{lrlllr}
\hline Fracture site & \multicolumn{2}{l}{ Men } & & \multicolumn{2}{l}{ Women } \\
\cline { 2 - 3 } \cline { 5 - 6 } & $\begin{array}{l}\text { No. of } \\
\text { cases }\end{array}$ & $\begin{array}{l}\text { Rate per } \\
10000 \text { py }\end{array}$ & & $\begin{array}{l}\text { No. of } \\
\text { cases }\end{array}$ & $\begin{array}{l}\text { Rate per } \\
10000 \text { py }\end{array}$ \\
& & & & & \\
\hline Any & 103052 & 99.5 & & 119317 & 107.1 \\
Radius/ulna & 13581 & 13.1 & & 33366 & 30.2 \\
Tibia/fibula/ankle & 15474 & 15.0 & & 16164 & 14.6 \\
Femur/hip & 5755 & 5.3 & & 19179 & 17.0 \\
Ribs & 10256 & 9.7 & & 7128 & 6.4 \\
Humereus & 5558 & 5.3 & & 11458 & 10.3 \\
Vertebral & 3406 & 3.2 & & 6195 & 5.6 \\
\hline
\end{tabular}

py, patient-years. 
was 665000 person-years (mean of 3.0 and median of 2.6 years per subject). During this period of observation 18283 patients sustained a second fracture at a different skeletal site.

A marked increase was found in the risk of future fracturing at other skeletal sites following an initial fracture, with rates of subsequent fracture 2-3 times higher than expected rates (Table 2). A patient with a radius/ulna fracture had a SIR of 3.0 for a fracture at a different skeletal sites. The ratio of observed to expected number of fractures was 2.0 for femur/hip and 5.8 for humerus in patients with a radius/ulna fracture. Patients with a vertebral fracture experienced rates of femur/hip fractures which were almost 3 times higher than expected (SIR 2.9). The SIR for subsequent rib fractures was 5.1. The risk of femur/hip fracture was strongly predicted by a history of fracture at any skeletal site. The SIR for femur/hip fracture was 2.8 for patients with a humerus fracture and 2.1 for patients with a tibia/fibula/ ankle fracture.

The SIRs were generally higher among men than women in patients aged 65 years or older (Table 3). Men aged 65-74 years with a history of radius/ulna or vertebral fractures had substantially higher rates of femur/hip fractures. The respective SIRs were 6.0 and 13.4. The corresponding SIRs among women of similar age were 3.3 and 5.8. The SIRs of subsequent fractures decreased with age. For subjects aged 65-74 years with a history of a radius/ulna fracture, the rate of further fracturing at other skeletal sites was 3.7 times higher than expected. For similar subjects aged 85 years or older, these rates were 2.2 times higher than expected.

Using lifetables, it was found that $3.1 \%$ of the men and $7.1 \%$ of the women aged 65 years or older sustained a femur/hip fracture within 5 years following a radius/ulna fracture (Fig. 1). For any fracture, these risks were $15.1 \%$ and $20.7 \%$, respectively. Men with a vertebral fracture aged 65 years or older had a 5-year risk of femur/hip fracture of $6.7 \%$ and women a risk of $13.3 \%$. For any fracture, this risk was $18.1 \%$ in men and $34.3 \%$ in women. Table 4 shows the 5 -year risk of subsequent fracture stratified by age and sex in patients aged 65 years or older. It was found that women aged 85 years or older had a $23.9 \%$ risk of a femur/hip fracture in the 5 years following the occurrence of a vertebral fracture.

Table 2. Standardized incidence ratio (SIR) of subsequent fractures stratified by fracture type in patients aged 20 years or older

\begin{tabular}{|c|c|c|c|c|c|c|c|}
\hline \multirow[t]{3}{*}{ Original fracture } & \multicolumn{7}{|l|}{ Later fracture } \\
\hline & \multirow{2}{*}{$\begin{array}{l}\text { Any fracture } \\
\text { SIR }(95 \% \mathrm{CI})\end{array}$} & \multirow{2}{*}{$\frac{\text { Radius-ulna }}{\operatorname{SIR}(95 \% \mathrm{CI})}$} & \multirow{2}{*}{$\frac{\text { Tibia/fibula/ankle }}{\text { SIR }(95 \% \text { CI })}$} & \multirow{2}{*}{$\frac{\text { Femur/hip }}{\operatorname{SIR}(95 \% \mathrm{CI})}$} & \multirow{2}{*}{$\begin{array}{l}\text { Humerus } \\
\text { SIR }(95 \% \mathrm{CI})\end{array}$} & \multirow{2}{*}{$\frac{\text { Ribs }}{\operatorname{SIR}(95 \% \mathrm{CI})}$} & \multirow{2}{*}{$\frac{\text { Vertebral }}{\operatorname{SIR}(95 \% \mathrm{CI})}$} \\
\hline & & & & & & & \\
\hline Any fracture & - & $2.5(2.4-2.6)$ & $2.3(2.2-2.4)$ & $2.2(2.1-2.2)$ & $3.5(3.3-3.6)$ & $2.3(2.2-2.4)$ & $2.2(2.0-2.3)$ \\
\hline Radius/ulna & $3.0(2.9-3.1)$ & - & $2.1(1.9-2.2)$ & $2.0(1.8-2.1)$ & $5.8(5.5-6.1)$ & $1.8(1.6-2.1)$ & $1.5(1.3-1.8)$ \\
\hline Tibia/fibula/ankle & $2.7(2.6-2.8)$ & $1.6(1.5-1.8)$ & - & $2.1(1.9-2.4)$ & $1.8(1.5-2.1)$ & $1.7(1.4-2.0)$ & $1.6(1.3-2.0)$ \\
\hline Femur/hip & $2.6(2.5-2.7)$ & $2.0(1.8-2.1)$ & $2.8(2.5-3.1)$ & - & $2.7(2.5-3.1)$ & $1.8(1.5-2.2)$ & $2.1(1.8-2.5)$ \\
\hline Humerus & $3.8(3.6-3.9)$ & $5.6(5.2-5.9)$ & $2.1(1.8-2.4$ & $2.8(2.5-3.0)$ & - & $2.6(2.2-3.2)$ & $2.8(2.3-3.4)$ \\
\hline Ribs & $2.6(2.4-2.7)$ & $2.1(1.9-2.4)$ & $2.2(1.9-2.6)$ & $2.1(1.8-2.4)$ & $2.7(2.3-3.2)$ & - & $4.3(3.7-5.2)$ \\
\hline Vertebral & $2.9(2.8-3.1)$ & $1.8(1.6-2.1)$ & $2.2(1.8-2.7)$ & $2.9(2.6-3.3)$ & $3.0(2.5-3.6)$ & $5.1(4.3-6.0)$ & - \\
\hline
\end{tabular}

Table 3. Standardized incidence ratio (SIR) of subsequent fractures stratified by age in patients aged 65 years or older

\begin{tabular}{|c|c|c|c|c|c|c|c|}
\hline \multirow{2}{*}{$\begin{array}{l}\text { Original } \\
\text { fracture }\end{array}$} & \multirow{2}{*}{$\begin{array}{l}\text { Later } \\
\text { fracture }\end{array}$} & \multicolumn{2}{|l|}{$65-74$ years } & \multicolumn{2}{|l|}{$75-84$ years } & \multicolumn{2}{|l|}{$85+$ years } \\
\hline & & $\begin{array}{l}\text { Men } \\
\text { SIR } \\
(95 \% \text { CI })\end{array}$ & $\begin{array}{l}\text { Women } \\
\text { SIR } \\
(95 \% \text { CI })\end{array}$ & $\begin{array}{l}\text { Men } \\
\text { SIR } \\
(95 \% \text { CI })\end{array}$ & $\begin{array}{l}\text { Women } \\
\text { SIR } \\
(95 \% \mathrm{CI})\end{array}$ & $\begin{array}{l}\text { Men } \\
\text { SIR } \\
(95 \% \text { CI })\end{array}$ & $\begin{array}{l}\text { Women } \\
\text { SIR } \\
(95 \% \text { CI })\end{array}$ \\
\hline \multirow[t]{3}{*}{ Any fracture } & Radius/ulna & $6.5(5.2-8.0)$ & $2.8(2.5-3.0)$ & $4.7(3.6-6.0)$ & $2.6(2.4-2.8)$ & $2.6(1.6-4.0)$ & $1.8(1.6-2.0)$ \\
\hline & Femur/hip & $5.2(4.2-6.5)$ & $3.6(3.3-4.0)$ & $4.4(3.7-5.2)$ & $2.8(2.7-1.9)$ & $2.8(2.2-3.5)$ & $1.9(1.7-2.0)$ \\
\hline & Vertebral & $5.3(3.8-7.1)$ & $2.8(2.4-3.3)$ & $3.5(2.5-4.8)$ & $2.2(1.9-2.5)$ & $2.5(1.3-4.1)$ & $1.9(1.5-2.2)$ \\
\hline \multirow[t]{3}{*}{ Radius/ulna } & Any fracture & $6.4(5.2-7.8)$ & $3.6(3.3-3.8)$ & $4.5(3.6-5.7)$ & $2.9(2.7-3.1)$ & $3.6(2.5-5.1)$ & $2.1(1.9-2.3)$ \\
\hline & Femur/hip & $6.0(3.4-9.9)$ & $3.3(2.8-3.9)$ & $2.7(1.5-4.5)$ & $2.7(2.4-3.0)$ & $2.8(1.5-4.9)$ & $1.8(1.6-2.1)$ \\
\hline & Vertebral & $4.0(1.3-9.4)$ & $2.2(1.6-3.0)$ & $1.9(0.4-5.7)$ & $1.6(1.2-2.1)$ & 0 & $1.6(1.0-2.4)$ \\
\hline \multirow[t]{3}{*}{ Femur/hip } & Any fracture & $8.1(6.4-10.1)$ & $3.9(3.5-4.4)$ & $4.3(3.5-5.3)$ & $3.1(2.9-3.4)$ & $2.8(2.0-3.8)$ & $2.1(2.0-2.3)$ \\
\hline & Radius/ulna & $10.0(5.7-16.2)$ & $2.5(2.0-3.2)$ & $4.3(2.3-7.2)$ & $2.8(2.4-3.2)$ & $1.1(0.2-3.3)$ & $1.6(1.4-1.9)$ \\
\hline & Vertebral & $11.4(5.5-21.0)$ & $3.8(2.3-5.8)$ & $3.3(1.4-6.5)$ & $2.5(1.9-3.2)$ & $2.7(0.9-6.3)$ & $1.7(1.2-2.3)$ \\
\hline \multirow[t]{3}{*}{ Vertebral } & Any fracture & $7.8(5.8-10.3)$ & $3.9(3.4-4.6)$ & $3.8(2.7-5.3)$ & $3.3(2.9-3.7)$ & $3.3(2.0-5.2)$ & $2.0(1.7-2.4)$ \\
\hline & Radius/ulna & $4.2(1.1-10.8)$ & $1.9(1.3-2.8)$ & $3.3(0.9-8.6)$ & $2.1(1.6-2.7)$ & $1.4(0.0-7.9)$ & $0.9(0.5-1.6)$ \\
\hline & Femur/hip & $13.4(7.3-22.5)$ & $5.8(4.1-8.1)$ & $4.5(2.4-7.5)$ & $4.2(3.5-4.9)$ & $2.3(0.8-5.0)$ & $2.1(1.6-2.7)$ \\
\hline
\end{tabular}


Table 4. Observed 5-year risk of subsequent fracture (lifetable estimates)

\begin{tabular}{|c|c|c|c|c|c|c|c|}
\hline \multirow[t]{2}{*}{ Original fracture } & \multirow[t]{2}{*}{ Later fracture } & \multicolumn{2}{|c|}{$65-74$ years } & \multicolumn{2}{|c|}{ 75-84 years } & \multicolumn{2}{|c|}{$85+$ years } \\
\hline & & Men & Women & Men & Women & Men & Women \\
\hline \multirow[t]{2}{*}{ Radius/ulna } & Femur/hip & $2.5 \%$ & $3.0 \%$ & $2.9 \%$ & $9.4 \%$ & $6.3 \%$ & $17.0 \%$ \\
\hline & Vertebral & $0.6 \%$ & $0.9 \%$ & $0.7 \%$ & $1.4 \%$ & 0 & $1.8 \%$ \\
\hline \multirow[t]{2}{*}{ Femur/hip } & Radius/ulna & $2.8 \%$ & $5.8 \%$ & $2.6 \%$ & $7.4 \%$ & $0.6 \%$ & $5.8 \%$ \\
\hline & Vertebral & $1.1 . \%$ & $1.5 \%$ & $1.3 \%$ & $2.2 \%$ & $3.2 \%$ & $1.5 \%$ \\
\hline \multirow[t]{2}{*}{ Vertebral } & Radius/ulna & $1.0 \%$ & $4.5 \%$ & $1.5 \%$ & $6.4 \%$ & $0.8 \%$ & $3.1 \%$ \\
\hline & Femur/hip & $5.7 \%$ & $6.2 \%$ & $7.4 \%$ & $15.5 \%$ & $8.8 \%$ & $23.9 \%$ \\
\hline
\end{tabular}
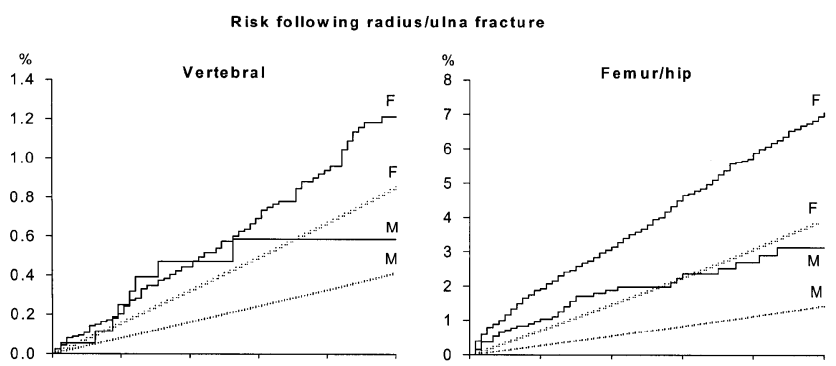

Risk following femur/hip fracture
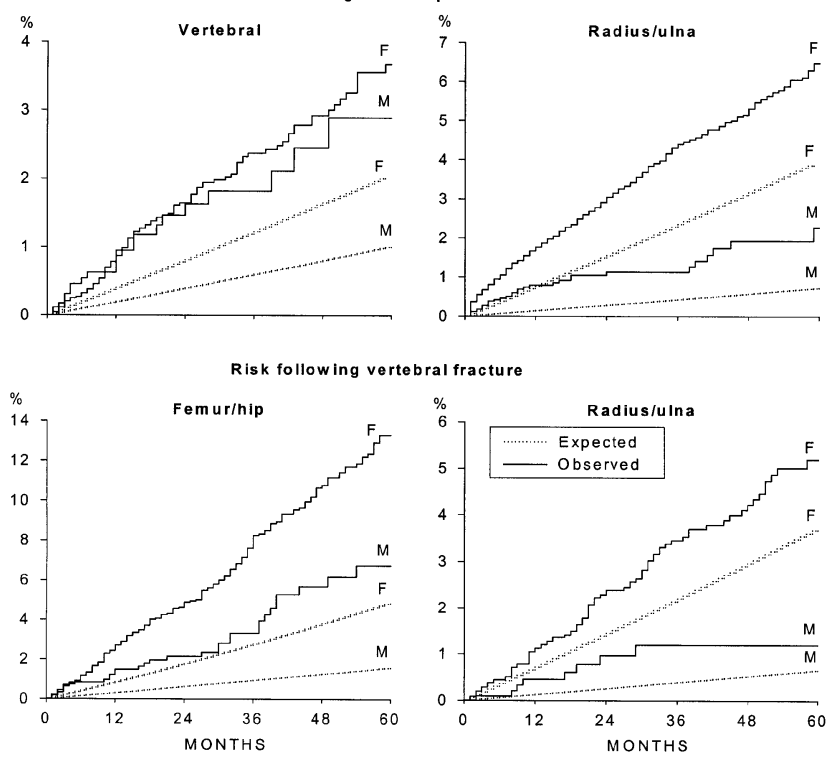

Fig. 1. Observed and expected incidence of fracture in patients aged 65 years or older stratified by sex (F, female; $M$, male).

\section{Discussion}

We found that the occurrence of a fracture substantially increased the likelihood of later fractures at different skeletal sites. Patients with a fracture were 2-3 times more likely to experience a fracture at another site. This increased risk was not restricted to a few skeletal sites, but was apparent across different sites and was found to be stable over time.
Our results regarding the risk of hip fracture following a vertebral fracture are consistent with other reports which suggest that there is at least a 2-fold increased risk of hip fracture after a vertebral fracture [5-8,10,14]. We found that this excess risk of further fracturing after a vertebral fracture was not restricted to the hip. Humerus fractures were increased 3-fold and rib fractures 5-fold following a vertebral fracture. Melton et al. [7] also observed that vertebral fractures are important predictors of future fracture risk at other skeletal sites, with an observed-to-expected ratio of 2.3 for humerus and 3.5 for rib fractures. Studies on the risk of hip fracture following a forearm fracture reported observed-toexpected ratios of about 1.5, which approximate our finding of a ratio of $2.0[9,12,13]$. With respect to the relationship between vertebral and forearm fractures, Black et al. [6] reported that there was only a small nonsignificant increased risk of wrist fracture in patients with vertebral deformities (age-adjusted relative rate of 1.4). In our study, there was a 1.8 -fold increased risk of forearm fracture following a vertebral fracture (primarily clinically symptomatic fractures confirmed radiographically). This excess risk was indeed smaller than that of hip fracture (SIR 2.9), but it was statistically significant. Finally, our results are in accord with a recent meta-analysis that reported a doubling of the risk of hip, spine and wrist fracture in patients with a fracture history [19].

Of interest was our finding that the relative risk of further fracturing was higher among men compared with women and higher among younger people compared with the elderly. In our study, a man aged 65-74 years with a femur/hip fracture had an 8-fold increased risk of further fracturing at another site compared with a 4-fold increased risk among women of a similar age. But a man aged 85 years or older with this fracture had only a 3 -fold increased risk relative to the general population of men of this age, and women a 2-fold increase. Our findings on the higher excess risk of further fracturing among men compared with women are consistent with the results of other studies [7,9,1114]. Malmin et al. [12] reported a relative rate of 2.3 for a subsequent hip fracture among men with a forearm fracture compared with a relative rate of 1.5 among women. Another larger study reported relative rates of further fracturing of 2.5 among men and 2.0 among women [13]. With respect to age, the results of previous 
studies are inconsistent, with reports of increasing relative rates of further fracturing with age [9], decreasing relative rates $[10,12]$ and no change $[7,8,13]$. This inconsistency could relate to differences in the mix of patients. Our finding of age and sex modification in the risk of further fracturing could reflect varying proportions of high-risk patients over age and sex. For example, if a fracture occurs primarily as a consequence of low bone density, the relative rate of further fracturing in the group of fracture cases compared with the general population will depend on the prevalence of low bone density in the general population. With a higher prevalence of high-risk patients, the rate of fractures in the general population, the control group, will be higher leading to a lower relative rate. This explanation is consistent with the observation that the largest age and sex modification of risk of further fracturing was generally seen among typical osteoporotic fractures, such as hip and vertebral fractures. Further studies are needed to confirm this hypothesis.

The risk of a further fracture was found to be large. For example, men with a vertebral fracture aged 65 years or older had an $18 \%$ (women had a $34 \%$ ) chance of suffering a fracture at another skeletal site within 5 years. These high risks support the need for further investigation if a fracture occurs. In the guidelines for diagnosis and treatment of osteoporosis, a fragility fracture of the hip, spine or wrist provides an indication for further investigations, such as bone densitometry $[3,4]$. Our findings suggest that fractures at other skeletal sites could also provide an indication for further review. In previous studies, forearm, ankle and vertebral fractures were associated with increased risks of almost all types of fracture $[7,11,13,14]$.

The risk of a repeat fracture at the same or opposite skeletal site was not evaluated in this study. The reason for this was that the medical records of the GPRD could contain repeated information about the same event. An event could be recorded at a later date as an indicator of a new treatment. Similarly, an event could be recorded following hospital admission or discharge. Another limitation of the study is the possibility of detection bias. A fracture history may have increased the likelihood of diagnosis of a new fracture due to greater awareness of physicians. This bias would be particularly relevant for those fractures that may have ambiguous symptoms and, thus, are difficult to diagnose. A third possible limitation concerned lack of lifetime data. The follow-up after a fracture was on average 3.0 years, up to a maximum of 9 years. Our observation that incidence ratios remained stable over time can thus not be extrapolated beyond these years. Other studies generally also found that the excess risk of further fracturing is fairly consistent over time, with up to 20 years of followup [6-8,13]. However, Johnell et al. [14] found in a study of a national hospital admission registry that the excess risk for hip fractures was most marked in the year following hospitalization for a vertebral fracture and that it declined up to 8 years later. The reason for this disparity is unknown. It was not reported whether hospital admissions could be linked to individual patient mortality data and whether the risk estimates were thus adjusted for the high first-year mortality following a vertebral fracture. Finally, the ascertainment of vertebral fractures was incomplete in this population as diagnoses were mostly based on the occurrence of clinical symptoms and only a small proportion of vertebral deformities reach clinical attention. This may not have substantively altered the incidence ratios as both expected and observed rates were underestimated.

This study demonstrates a marked increase in the risk of future fracturing at other skeletal sites following an initial fracture. This association was not restricted to a few skeletal sites but existed across different sites, with increases of 2 to 3 times the expected rate in the general population. Our results indicate that a history of a fracture is a strong risk factor for new fractures. An application of the present findings might be to consider any fracture history as part of the clinical indications for bone densitometry.

Acknowledgements. The study was funded by Procter \& Gamble Pharmaceuticals. We thank EPIC, the GPRD licence holder, for their support.

\section{References}

1. Consensus development conference. Diagnosis, prophylaxis and treatment of osteoporosis. Am J Med 1993;94:646-50.

2. Compston JE, Cooper C, Kanis JA. Bone densitometry in clinical practice. BMJ 1995;310:1507-10.

3. Kanis JA, Delmas P, Burckhardt P, Cooper C, Torgerson D. Guidelines for diagnosis and management of osteoporosis. Osteoporos Int 1997; 7:390-406.

4. Royal College of Physicians. Clinical guidelines for the prevention and treatment of osteoporosis. London: RCP, 1999.

5. Cooper C, Kotowicz M, Atkinson EJ, O'Fallon WM, Riggs BL, Melton LJ III. Risk of limb fractures among men and women with vertebral fractures. In: Papapoulos SE, Lips P, Pols HAP, Johnston CC, Delmas PD, editors. Osteoporosis 1996. Amsterdam: Elsevier, 1996:101-4.

6. Black DM, Arden NK, Palermo L, Pearson J, Cummings SR. Prevalent vertebral deformities predict hip fractures and new vertebral deformities but not wrist fractures. J Bone Miner Res 1999; $14: 821-8$.

7. Melton LJ III, Atkinson EJ, Cooper C, O’Fallon WM, Riggs BL. Vertebral fractures predict subsequent fractures. Osteoporos Int 1999; 10:214-21.

8. Kotowitz MA, Melton LJ III, Cooper C, Atkinson EJ, O'Fallon WM, Riggs BL. Risk of hip fracture in women with vertebral fracture. J Bone Miner Res 1994;9:599-605.

9. Owen RA, Melton LJ III, Ilstrup DM, Johnson KA, Riggs BL.Colles' fracture and subsequent hip fracture risk. Clin Orthop 1982;171:37-43.

10. Lauritzen JB, Lund B. Risk of hip fracture after osteoporotic fractures. Acta Orthop Scand 1993;64:297-300.

11. Karlsson MK, Hasserius R, Obrant KJ. Individuals who sustain nonosteoporotic fractures continue to also sustain fragility fractures. Calcif Tissue Int 1993;53:229-31.

12. Malmin H, Ljunghall S, Persson I, Naessen T, Krusemo UB, Bergstrom R. Fracture of the distal forearm as a forecaster of subsequent hip fracture: a population-based cohort study with 24 years of follow-up. Calcif Tissue Int 1993;52:269-72.

13. Cuddihy MT, Gabriel SE, Crowson CS, O'Fallon WM, Melton LJ III. Forearm fractures as predictors of subsequent osteoporotic fractures. Osteoporos Int 1999;9:469-75. 
14. Johnell O, Oden A, Coulin F, Kanis JA. Acute and long-term increase in fracture risk after hospitalization for vertebral fracture. Osteoporos Int 2001;12:207-14.

15. Walley T, Mantgani A. The UK general Practice Research Database. Lancet 1997;350:1097-9.

16. van Staa TP, Dennison EM, Leufkens HGM, Cooper C. Epidemiology of fractures in England and Wales. Bone 2001;29:517-22.

17. van Staa TP, Abenhaim L, Cooper C, Begaud B, Zhang B, Leufkens HGM. The use of a large pharmaco-epidemiological database to study exposure to oral corticosteroids and risk of fractures: validation of study population and results. Pharmacoepidemiol Drug Saf 2000;9:359-66.

18. Greenland S, Rothman KJ. Introduction to categorical analysis. In: Rothman KJ, Greenland S, editors. Modern epidemiology. Philadelphia: Lippincott-Raven, 1998:231-52.

19. Klotzbuecher CM, Ross PD, Landsman PB, Abbott TA III, Berger M. Patients with prior fracturs have an increased risk of future fractures: a summary of the literature and statistical synthesis. J Bone Miner Res 2000;15:721-7.

Received for publication 19 November 2001 Accepted in revised form 13 February 2002 